Table I. Results of viral serology in 67 children with transient synovitis of the hip

\begin{tabular}{ll}
\hline Pathogen & $\begin{array}{l}\text { Percentage } \\
\text { of patients }\end{array}$ \\
\hline Non-specific positive & 46.2 \\
Mycoplasma & 12.8 \\
Rubella & 10.3 \\
Enterovirus & 9.0 \\
Epstein-Barr & 7.7 \\
Mumps virus & 6.4 \\
Adenovirus & 5.1 \\
Measles virus & 2.6 \\
\hline
\end{tabular}

b) 9 with high titres to more than one pathogen;

c) 7 with a raised titre to Epstein-Barr virus; and

d) 12 with high titres to only one pathogen.

Thirty-six patients had no serological evidence of infection, and of these, $26(76 \%)$ had normal blood interferon levels.

Discussion. It is clear that the interferon system is an important part of the defence against viral infections (Levin 1983). Interferons are a group of cytokines (glycoproteins) secreted by cells in the body after stimulation by various antigens and micro-organisms, especially viruses, and they act as messengers to activate the immune system. The entry of a virus into a cell leads not only to replication of the virus, but to the production of interferon which is secreted within hours into the surrounding media. This could be the pathological basis of our finding that synovial fluid interferon levels were raised in almost all the samples tested. Such local production could be the first response to any viral infection.

Leibowitz et al (1985) found that blood interferon levels were significantly raised in $40 \%$ of patients with acute transient synovitis. In normal healthy subjects these levels are usually not measurable, but various viral diseases cause significantly raised concentrations. Our findings for blood interferon levels agree with those of Leibowitz et al and help to confirm that the interferon system is activated in transient synovitis. In addition, our study has demonstrated raised interferon levels in the joint fluid itself.

No benefits in any form have been received or will be received from a commercial party related directly or indirectly to the subject of this article.

\section{REFERENCES}

Leibowitz E, Levin S, Torten J, Meyer $\mathbf{R}$. Interferon system in acute transient synovitis. Arch Dis Child 1985; 60:959-62.

Levin S. Interferon in acute viral infections. Eur J Pediatr 1983; 140: 2-4.

\title{
SCAPHOID FRACTURE AT THE TIP OF A HERBERT SCREW
}

JOHN STOTHARD, ASHOK KUMAR

The Herbert differential pitch screw has given encouraging results for unstable fracture, delayed union and nonunion of the waist of the scaphoid (Herbert, Fisher and Leicester 1992), and has also been recommended for use in other small bone fragments. Some technical difficulties have been reported (Ford et al 1987; Pring, Hartley and Williams 1987), but to our knowledge scaphoid fracture after the use of a Herbert screw has not been described. Such fractures may result from the tip of the screw acting as a 'stress riser', or to late avascular

J. Stothard, MD, FRCS, FRCS Orth, Consultant Orthopaedic and Hand Surgeon

A. Kumar, FRCS, Registrar in Orthopaedic Surgery

Department of Orthopaedics, North Tees General Hospital, Hardwick, Stockton-on-Tees, Cleveland TS19 8PE, UK.

Correspondence to $\mathrm{Mr}$ J. Stothard.

(C) 1993 British Editorial Society of Bone and Joint Surgery

0301-620X/93/6R84 \$2.00

J Bone Joint Surg [Br] 1993; 75-B: 974-5.

Received 28 January 1993; Accepted 22 February 1993 necrosis of the proximal fragment. We report two cases which illustrate these problems.

Case 1. A left-handed 25-year-old man had a successful Herbert screw and graft for nonunion ten months after a fracture of the waist of the scaphoid (Figs 1,2). Seven years later, he fell from his cycle, landed on his knuckles, and sustained a new fracture (Fig. 3). He was treated in plaster but defaulted from review.

Case 2. A 38-year-old man sustained a fracture through the waist of the right scaphoid (Fig. 4) and was treated in plaster. After three months the fracture had not united, and Herbert screw fixation was performed. There was satisfactory clinical and radiological union at five months (Fig. 5).

Three years later, wrist pain began after heavy manual work, but there was no definite injury. Radiographs obtained later showed probable avascular necrosis of the proximal pole with clearly visible radiolucency around the distal threads of the screw (Fig. 6).

Discussion. Herbert screws are made of titanium and do not need removal; attempted removal is likely to cause 


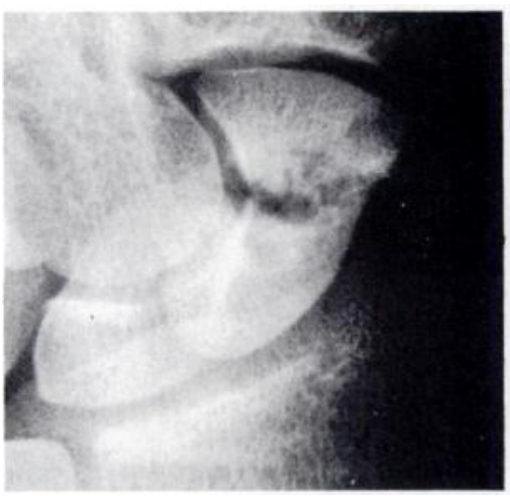

Fig. 1

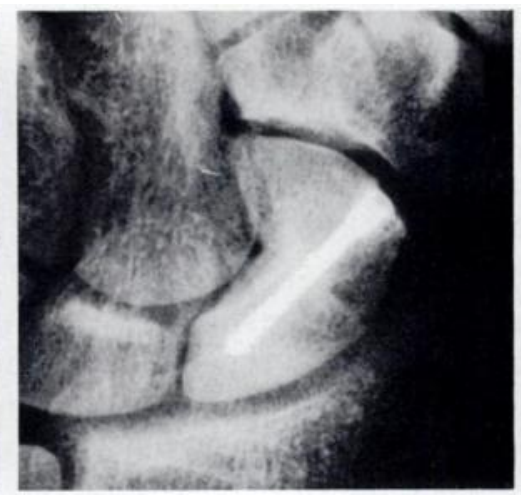

Fig. 2

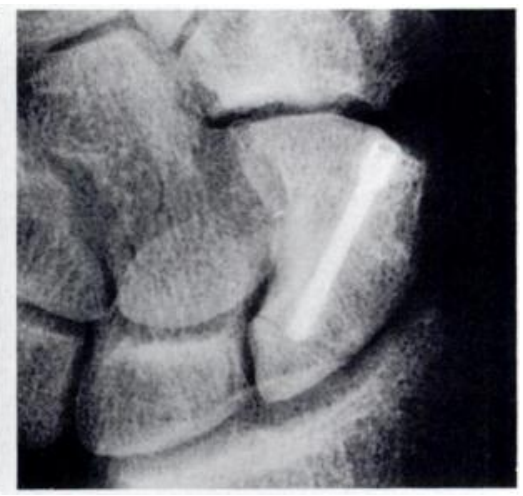

Fig. 3

Case 1. Ununited scaphoid waist fracture (1), united seven months after insertion of a Herbert screw and bone graft (2). A new fracture occurred seven years later (3).

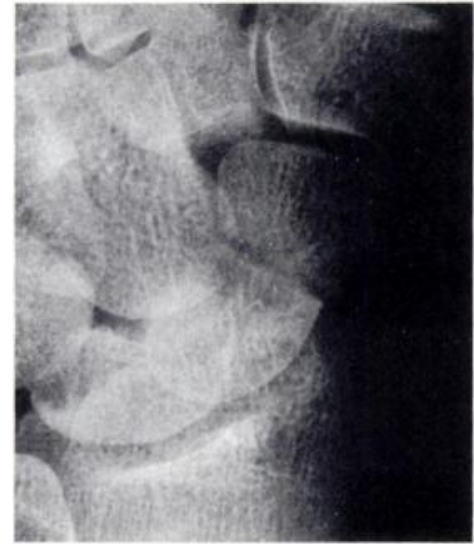

Fig. 4

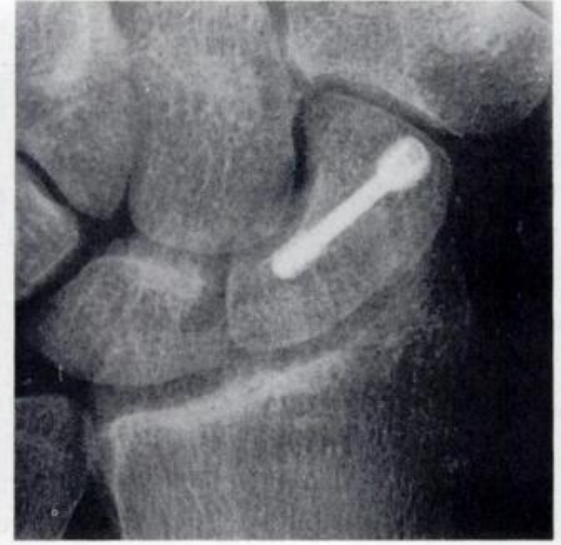

Fig. 5

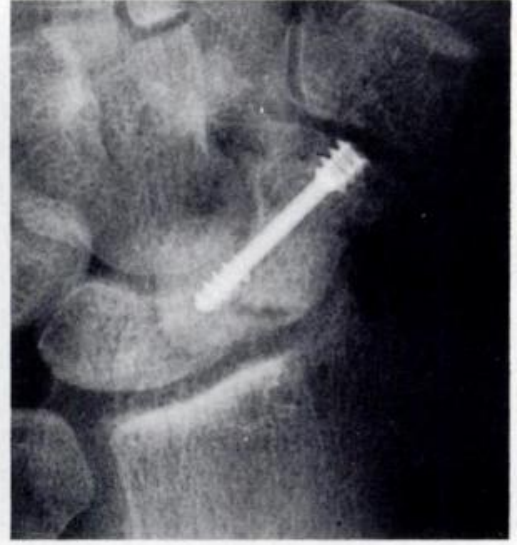

Fig. 6

Case 2. Ununited scaphoid waist fracture (4), united five months after insertion of a Herbert screw and bone graft (5). Three years later, there is a new fracture in a probably avascular proximal pole (6).

damage to the scaphotrapezial joint. There have, however, been reports of radiological loosening of a Herbert screw in long-standing nonunion (Moran and Curtin 1988), of the trapezium impinging on a protruding screw head (Ford et al 1987), and of poor screw placement leading to unsatisfactory results (Pring et al 1987). Various technical difficulties have been documented (Bunker, McNamee and Scott 1987).

Radiological assessment of union of the scaphoid is very difficult particularly in the presence of a screw and bone graft. Even multiple views may fail to show definite union, and the term 'probable union' has been used. Patients may remain symptom-free while the screw stabilises the fragments, but in the absence of true union progressive avascular necrosis may weaken the bone, and the tip of the screw may act as a 'stress riser'.

We suggest that the late complication of a new fracture at the tip of the screw may be avoided by ensuring that the screw traverses the full length of the bone, reaching to the tip of the proximal pole. To ensure this, we now use radiography during all operations for insertion of a Herbert screw. This is to confirm correct jig placement and also to show that the tip of the drill has not deviated from correct alignment with the tip of the $\mathrm{C}$-arm of the jig. There is a strong tendency to deviate towards the scaphocapitate joint; and if the screw is inserted in this direction it cannot pass to the end of the proximal pole.

No benefits in any form have been received or will be received from a commercial party related directly or indirectly to the subject of this article.

\section{REFERENCES}

Bunker TD, McNamee PB, Scott TD. The Herbert screw for scaphoid fractures: a multicentre study. J Bone Joint Surg [Br] 1987; 69B : $631-4$

Ford DJ, Khoury G, El-Hadidi S, Lunn PG, Burke FD. The Herbert screw for fractures of the scaphoid: a review of results and technical difficulties. J Bone Joint Surg [Br] 1987; 69-B:124-7.

Herbert TJ, Fisher WE, Leicester $A W$. The Herbert bone screw : a ten year perspective. $J$ Hand Surg [Br] 1992; 17-B:415-9.

Moran R, Curtin J. Scaphoid fractures treated by Herbert screw fixation. J Hand Surg [Br] 1988; 13-B:453-5.

Pring DJ, Hartley EB, Williams DJ. Scaphoid osteosynthesis: early experience with the Herbert bone screw. J Hand Surg [Br] 1987; $12-B: 46-9$. 